\title{
Limites e possibilidades do Sistema Único de Saúde utilizando a imagem pendular da relação entre 0 Estado e o Mereado
}

\author{
Limits and possibilities of Single Health System \\ using the pendulum image of relation between \\ State and Market
}

Danielle de Melo Tenório ${ }^{1}$

\section{Resumo}

A dinâmica pendular busca o ponto de equilíbrio entre o Mercado e Estado, cabendo ao Estado a missão de intervenção, observando a sociedade. Ela consiste em duas referências ordenadoras: Estado e Mercado. O Estado está do lado esquerdo e o mercado do lado direito e o pêndulo se configura na sociedade oscilando de acordo com seus princípios e necessidade de cada sociedade em determinada época. Quando esse pêndulo se direciona a direita para o Mercado os mecanismos da sociedade estão direcionados para o lucro, a disputa econômica e todas as ações e serviços prestados tem como finalidade o retorno econômico, ou seja, somente quem pode pagar por tais serviços é quem pode desfrutá-los, inversamente do que ocorre quando o pêndulo se inclina para a esquerda (o Estado), pois é o Estado que assume a responsabilidade e o dever de oferecer os serviços e assistência a sociedade não visando lucratividade. Este ensaio vislumbra refletir sobre os aspectos em que a visão pendular pode servir para análise da saúde e do Sistema Único de Saúde como produto de uma conformação social e econômica no Brasi contemporâneo.

\section{Abstraet}

The dynamics pendulum seeks balance between market and state, while the State's mission to intervene by observing the society. It consists of two references ordered: State and Market.The State is from the left and Market the right side of the pendulum. It swings in society is shaped in accordance with its principles and requirements of each society during differents historical periods. When the pendulum is directed to market side, the mechanisms of society are targeted for profit. The economic dispute and all actions and services is aimed at the economic return, in other words, only those who can afford such services who can enjoy them. Conversely when the pendulum is tilted to the left (the state), it is the State assuming the responsibility and duty to provide services and assistance the company is not seeking profit. This essay find to reflect on the ways in which the pendulum can be used to view analysis of health and the Health System as a product of social and economic conditions in shaping Brazil in contemporaniety.

\author{
'Nutricionista, Espeeialista em Saúde Públiea - Estudante de Especialização \\ em Gestão em Saüde Pübliea - Universidade de Pernambuco. \\ Para correspondência: \\ Danielle Tenório \\ email:dtmarrocos@hotmail.com
}

Data da Submissão: 24/11/2010 Data do Aceite: 24/12/2010 
Introdução

A nova dinâmica social produzida pela legislação trará à tona, daí em diante, a falsa estabilidade e o forte caráter fetichista existente na 'assistência à saúde' dos planos privados. Este setor vai mergulhar numa agenda de conflitos e reclamos relativos às disputas de interesses do governo, das operadoras, dos prestadores e usuários/consumidores. Cenário muito influenciado pela mobilização social que passa a exigir outro tratamento para a questão do sistema privado de atenção à saúde e, para o qual, torna relevante a inexistência, ou insuficiência, de legislação reguladora (Aciole, 2004).

Entretanto, durante a trajetória dos 20 anos do SUS e do Código de Defesa do Consumidor, tem se aprofundado a crise de ajuste estrutural da economia do país às novas injunções do capitalismo mundial, com reflexos na ordenação das políticas públicas. Nesse processo, setores vitais, como a saúde e a educação, assistiram a adoção de políticas segmentadas, focais e compensatórias, que restringem o escopo de ação do Estado a um mínimo - a uma cesta básica de procedimentos - enquanto se alargam as bases de atuação do mercado privado. Situação esta reveladora de uma certa tensão e crise nos caminhos de consolidação de um modelo amplo, eficiente e universal de assistência à saúde, e que alimenta o dinamismo e a tensão interna à sociedade civil.

\section{A imagem pendular e a relação entre Estado e Mercado}

A imagem metafórica do pêndulo social, oscilando entre direita e esquerda, pode bem ilustrar a alternância entre os princípios dominantes de organização das relações sociais, mas é insuficiente para explicar como, em cada momento específico, as relações entre o Estado e o mercado, de fato, se estabelecem. Para esse movimento, a figura mais adequada é a da espiral, que agrega uma outra dimensão nesse movimento.

Além de oscilar entre os princípios opostos à direita e à esquerda, as relações entre Estado e mercado assumem conformações distintas no espaço ao longo tempo, de forma que não se possa, rigorosamente, falar de retorno a um ponto de partida, como seria o caso do pêndulo de um relógio. Dito de outra forma, as relações entre Estado e mercado nunca se repetem no tempo, renovando-se constantemente .

O recorte liberal (ou neoliberal, como prefere a maioria) coloca, de maneira evidente, que tamanho deve ter o público para que não atrapalhe o privado: o agente público deve atuar perante a ausência do agente privado, ou se ausentar para não atrapalhar a harmonia imanente às relações privadas. $\mathrm{O}$ Estado deve, quando muito, regulamentar o mercado, mas não a ponto de impedir que este viceje e se consolide. Onde as condições de mercado sejam ausentes ou insuficientes, aí deve estar o Estado em ações corretivas ou compensatórias. Ou ainda, o Estado deve restringir-se a um conjunto de funções específicas, mas genéricas o suficiente, para ficar longe de concorrer com o setor privado. Neste processo, Estado e Mercado, enquanto setores emblemáticos da dualidade público/privado, acabam sendo reconhecidos como entidades antagônicas, separadas, distintas, embora permaneçam ligados pela trama social em que se estabelecem e que, simultaneamente, os estabelece.

De fato, os profetas e apóstolos da supremacia do mercado centram-se na defesa de que uma mão invisivel contribuirá para a auto-regulação e se encarregará de produzir a justa e equânime distribuição de riqueza. $\mathrm{O}$ projeto liberal se utiliza deste reconhecimento para alimentar reafirmações da supremacia do mercado sobre o Estado, ressaltando para este o papel de obstáculo às condições gerais de desenvolvimento econômico enquanto lugar da ineficiência, do desperdício, da inoperância, de empecilho da plenitude daquele. É principalmente por esta razão que o Estado deve ser reformado de modo a se adequar à nova realidade afirmada na (e pela) supremacia do mercado em geral.

Embora, como Marx, aponte o fato de que a sociedade moderna esteja voltada para as necessidades do homem, o pensador alemão também discorda de que, no caso moderno, estas necessidades estejam orientadas pelo fato de que o trabalho passou a ocupar lugar central na nova sociedade, assumindo a esfera de preocupação pública, haja vista que é de sua exploração que se constrói e reproduz o capital. Neste particular, adverte-nos, pouco importa se uma nação se compõe de homens iguais ou desiguais, pois a sociedade contemporânea exige que os seus membros ajam como se fossem membros de uma enorme família dotada apenas de uma opinião e de um único interesse. E mais, a sociedade equaliza sempre e em quaisquer circunstâncias, exibindo como signo moderno a igualdade, elemento 
intrínseco que amalgama o social.

A vitória da igualdade no mundo moderno é, para ela, fruto do reconhecimento jurídico e político de que a sociedade conquistou a esfera pública, e que a distinção e a diferença reduziram-se a questões privadas do indivíduo. Segundo a visão marxista, o mercado é o elemento constituinte das relações sociais do novo modo de produção, como lugar de circulação e troca do capital: nele se colocam, de um lado, os compradores da força de trabalho, isto é, os proprietários do capital e, do outro lado, os vendedores, que só dispunham de sua força de trabalho, que se constitui em típica mercadoria, o principal produto a ser obtido no mercado. É por intermédio da sua força de trabalho que os indivíduos, organizados socialmente de modos historicamente determinados, produzem objetos, produzem a si mesmos e produzem a sobrevivência da espécie. A equação entre consumo de força de trabalho num determinado período de tempo é que realiza o valor dos produtos do trabalho humano.

Este tempo, que a força de trabalho utiliza na produção, é definido pela organização da sociedade construída historicamente segundo seus interesses e necessidades: por conta disso, pode-se falar em tempo de trabalho socialmente necessário como definidor de valor dos produtos. $\mathrm{O}$ valor sugere a generalização do trabalho humano como mercadoria, no que tem sido o motor do desenvolvimento da sociedade moderna e do capitalismo. Marx (1996) acrescenta que o fator 'equivalente' se constitui no mecanismo que possibilita a apropriação privada do processo de trabalho coletivo realizado por sujeitos individuais. Ao dissecar este mecanismo, acaba por construir uma conceituação revolucionária, e moderna, para o conceito de propriedade, que não constitui mais parte fixa e firmemente localizada no mundo, adquirida por seu detentor de uma maneira ou de outra; ao contrário, passa a ter no próprio homem a sua origem, mais precisamente no corpo e na propriedade de força deste corpo, a que ele denominou de 'força de trabalho'.

Da capacidade da força de trabalho em produzir um excedente além do necessário para a obtenção das condições de sobrevivência, e da capacidade do capital em remunerar a compra desta força sempre mais próxima do limite de atendimento das necessidades materiais de sobrevivência do trabalhador, resulta a expropriação deste excedente, que constitui a mais-valia: unidade essencial que era capturada pelo capital em sua forma de conversão do trabalho! Trabalho convertido em capital constituía capacidade de adquirir trabalho que era capturado pelo capital. Gênese de relação contraditória sobre a qual, contudo, se assenta a possibilidade de apropriação privada do produto coletivo.

No Brasil, trava-se uma luta política essencial em torno da consolidação de projetos cujo cerne passa pela afirmativa singular do papel do Estado, e de sua configuração, que se vislumbra um contexto ideológico em que se reconhecem distintos modelos de espaço público, somente invisível se nela não colocarmos as cores de Ercília (Costa, 2002). Na saúde, em particular, a discussão passa pelo aprofundamento das raízes que foram conformando dois sistemas de atenção, um estatal, outro privado, e dos vínculos entre eles. Neste contexto ideológico, temos cotidianamente afirmada uma distância praticamente intransponível, posta na afirmação da diferença entre ser usuário do sistema público versus ser consumidor dos planos de saúde do sistema privado, revelada à luz das estratégias e ações com que as corporações profissionais e os movimentos sociais, por exemplo, disputam projetos e modos de organizar a assistência à saúde e à doença.

\section{Imagem pendular 80 “caso da saúde”}

No caso da saúde, esta clivagem tem recebido sustentação ideológica que separa "usuários" de "consumidores", e que se estrutura com base em pares de opostos: preventivo $x$ curativo, rede básica $x$ hospital, ações coletivas $x$ ação individual, saúde pública $x$ medicina, liberdade de escolha versus controle e agilidade e eficiência versus burocracia, descaso, filas e regulação. Com isso, o Ministério da Saúde tenta substituir a estratégica adotada anteriormente, qual seja, a de induzir a tomada de decisões no âmbito estadual e municipal a partir de incentivos financeiros, por uma outra centrada no compromisso político entre os gestores, a ser construído no espaço das Comissões Intergestores Tripartite, ao nível nacional, e das Comissões Intergestores Bipartites, em cada estado, mediante a assinatura de "Termos de Compromisso" pactuados politicamente. Esse movimento pode ser interpretado de vários ângulos.

Do ponto de vista político mais geral, essa reorientação pode ser atribuída à existência de concepções distintas acerca da forma de exercício do poder nos atores que compõem as diversas forças 
políticas em cena no processo de construção do SUS, as quais se expressam nos discursos e nas decisões adotadas pelos dirigentes das instituições gestoras nos diversos níveis. Como parte dessa totalidade de mudanças , defendia o princípio de que a saúde era um direito de todos e um dever do Estado, propondo a instalação de um Sistema Único de Saúde, democrático e descentralizado, com responsabilidades estabelecidas para as três esferas de governo. Enquanto processo, a Reforma Sanitária enfrentou-se com obstáculos consideráveis nos últimos vinte anos, apesar das conquistas indiscutíveis.

Além da insuficiência e instabilidade do financiamento público para o SUS, persistem problemas de gestão, especialmente no que diz respeito aos estabelecimentos de saúde como hospitais e serviços de atenção básica. A falta de profissionalização de gestores, a descontinuidade administrativa, o clientelismo político e a interferência político-partidária no funcionamento dos serviços comprometem a reputação do SUS perante os cidadãos e a expectativa dos servidores públicos Enfrentar o desafio de construir uma "nova institucionalidade" para o SUS significa, portanto, debruçar-se sobre os problemas e desafios que emanam da atual configuração macroorganizacional do sistema e do processo de gestão nos vários níveis do sistema, de modo a subsidiar a identificação de propostas alternativas que contribuam para o fortalecimento e a consolidação de práticas coerentes com os princípios e valores da Reforma Sanitária. Daí a necessidade de ressaltar o caráter republicano do SUS e a Reforma Sanitária Brasileira como um projeto civilizatório.

A opinião pública cumpre uma importante função política: a consolidação do pensamento burguês e a colonização deste espaço pelos formadores de opinião, pelos formadores do senso comum. Estes são o público que lê, pensa, se manifesta e consolida uma imagem do mundo comum à semelhança do que lê e ouve. Esta é uma ação fundamental desde a queda dos regimes absolutistas e a ascensão da nova classe burguesa na sua luta pela hegemonia política e conquista do poder, que praticamente obriga:

"todas as nações a adotarem o modo burguês de produção, (...) a abraçar a chamada civilização, isto é, a se tornarem burguesas" (Marx $\mathcal{E}$ Engels, 1998).

\section{Conclusões}

Assim investido, o Estado intervém profundamente no intercâmbio de mercadorias e no trabalho social, por meio de leis e de medidas administrativas, vinculadas aos interesses dominantes que buscam perturbações mínimas nas condições ideais de funcionamento da produção econômica, o que imprime uma ambigüidade peculiar às relações de regulação e organização do espaço: admitem ser regulamentados tanto quanto querem ser deixados livres em suas iniciativas. Além disso, a ambigüidade do intervencionismo estatal no mercado tende a estar ligada aos interesses da sociedade burguesa, e ao mesmo tempo, deverá se constituir de forma separada daquela. Esta ambivalência peculiar acaba por se alocar em sítios específicos: a regulamentação pública ao Estado e a iniciativa privada ao mercado. Estado e Sociedade civil constituirão, enfim, duas esferas distintas: pública e privada. Resistindo ao intervencionismo, a sociedade civil e burguesa se constitui em contrapeso à autoridade do Estado; este, por seu turno, vai se ancorar num interesse privado, próprio daqueles que controlam o exercício do poder estatal, que se consolida como algo tangenciável apenas pelos que lhe são subordinados, isto é, as pessoas privadas excluídas da participação no poder público.

\section{Referêneias}

1. Carta de Brasília. Documento final do $8^{\circ}$ Simpósio sobre Política Nacional de Saúde. Medicina CFM 2005; 156:12-13.

2. Testa M. Pensar em saúde. Porto Alegre: Artes Médicas/ABRASCO; 1992.

3. Testa M. Análisis de instituciones hipercomplejas. In: Merhy EE, Onocko R, organizadores. Agir em saúde: um desafio para o público. São Paulo: Hucitec; Buenos Aires: Lugar Editorial; 1997. p.17-70.

4. Nogueira MA. As possibilidades da política. Idéias para a reforma democrática do Estado. Rio de Janeiro: Paz e Terra; 1998.

5. Brasil. Ministério da Saúde. Sistema Único de Saúde. Descentralização das ações e serviços de saúde: a ousadia de cumprir e fazer cumprir a Lei. NOB 01/93. Brasília: Ministério da Saúde; 1993.

6. Levcovitz E, Lima LD, Machado CV. Políticas de Saúde nos anos 90: relações intergovernamentais e o papel das Normas Operacionais Básicas. Rev C S Col 2001; 6(2):269-291.

7. ABRASCO, CEBES, ABRES, Rede Unida, AMPASA. Manifesto: Reafirmando compromissos pela saúde dos brasileiros. Brasília: ABRASCO, CEBES, ABRES, Rede 
Unida, AMPASA; 2005.

8. Campos GWS. O público, o estatal, o privado e o particular nas políticas públicas de saúde. In: Heimann LS, Ibanhes LC, Barboza R. O público e o privado na saúde. São Paulo: Hucitec; 2005. p. 89-110. 